\title{
Spatial and temporal aspects of slope hazards along a railroad corridor in the Canadian Cordillera
}

\author{
R. Macciotta Department of Civil and Environmental Engineering, University of Alberta, Canada \\ D.M. Cruden Department of Civil and Environmental Engineering, University of Alberta, Canada \\ C.D. Martin Department of Civil and Environmental Engineering, University of Alberta, Canada \\ N.R. Morgenstern Department of Civil and Environmental Engineering, University of Alberta, Canada \\ M. Petrov Department of Civil and Environmental Engineering, University of Alberta, Canada
}

\begin{abstract}
A successful slope management program depends on understanding the interaction between the potential slope failure and the elements at risk. This interaction defines the magnitude and likelihood of the potential consequences, which in turn defines the need for allocating resources for risk mitigation. The interaction can be divided into the probability of interaction between the displaced material and the elements at risk, and the degree of loss should impact occur. In this paper, the temporal and spatial aspects of landslides are analysed along a section of a railroad corridor through the Canadian Cordillera. The temporal and spatial aspects of the elements at risk are discussed and illustrated within the context of railroad freight train operations. An example is presented where the annual frequency of interaction between landslides and freight trains is estimated, and the associated spatial and temporal variability analysed. The paper highlights the importance, within a slope risk management strategy, of understanding landslide trends in space and time and how these spatial and temporal trends are related to morphology, geology and triggering mechanisms.
\end{abstract}

\section{Introduction}

Transportation corridors through the Canadian Cordillera required steep cuts in rock slopes to accommodate railroads and highways. As previously documented, slope hazards are common in these corridors, rockfalls being the most frequent type of slope instability (Bunce et al., 1997; Evans and Hungr, 1993; Hungr et al., 1999; Hoek, 2007; Dorren, 2003). In particular, railroads across the Canadian Cordillera have long histories of losses caused by ground hazards, slope failures (mainly rockfalls) being the most frequent (Hungr et al., 1999; Lan et al., 2010).

The valley formed by the Fraser River hosts an important transportation corridor between the City of Vancouver and the interior of British Columbia. This corridor cuts through the Canadian Cordillera and is used by the Canadian Pacific Railway (CP), the Canadian National Railway Company (CN), and one of Western Canada's major highways (Highway 1). The Fraser valley narrows upstream north of the town of Hope, and for the first 40 miles to the north between Hope and Boston Bar (Figure 1), landslides mostly consist of rockfalls and rock slides of planar or wedge type (Piteau, 1977; Lan et al., 2007; Macciotta et al., 2011). The steepness of the rock slope cuts cause slope failures, originating as slides or topples to, detach from the slope and fall onto or near the road and railroad tracks. Most of these events are therefore reported as rockfalls. In this paper, rockfalls, slides and topples originating from the rock slope cut are referred to as landslides.

These landslides along transportation corridors are high frequency - low consequence threats. The slope instabilities considered within the definition of landslides in this paper exclude larger instabilities, which would need to be managed as site-specific, low probability - high consequence threats. 

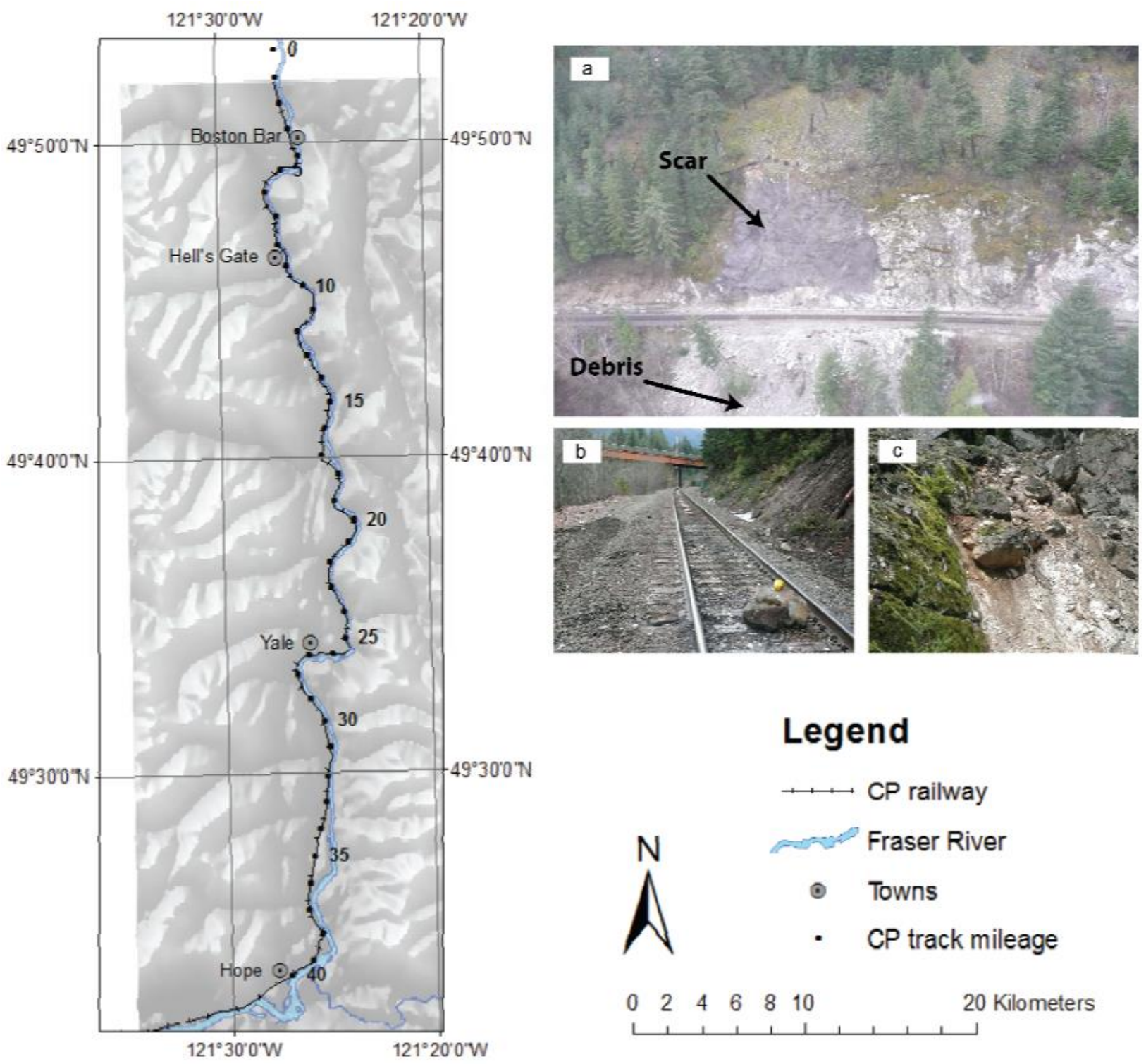

\section{Legend}

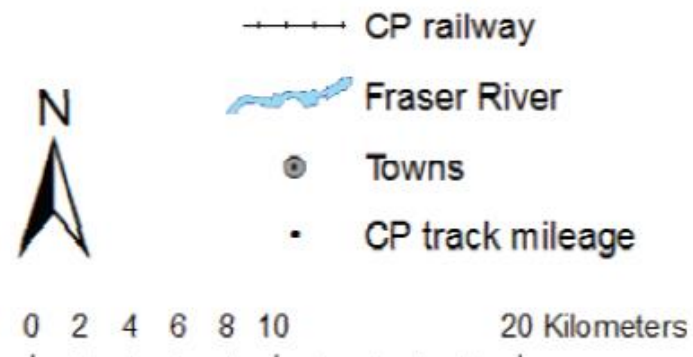

Figure 1 Study area location and slope stability problems along CP's Cascade subdivision; (a) steep cut at mile 2.9, typical of the section between Boston Bar and Yale. Scar covered with shotcrete and debris from previous events are evident; (b) typical rockfall deposit at mile 14.6; (c) unstable blocks at mile 5.7 (CP pers. comm.) (Macciotta et al., 2011)

Landslide risk can be divided into the probability of interaction between the fallen debris and the elements at risk (probability of impact), and the degree of loss should impact occur. For a slope management program to be successful, the interaction between the potential landslides and the exposed elements (elements at risk) need to be understood. This interaction defines the potential consequences of a landslide event in terms of magnitude and likelihood. When assessing hazardous transportation corridors, consequence magnitude and likelihood in turn define the sections in need of resources for risk mitigation (Hunt, 1992; Guzzetti et al., 2004; Roberds, 2005).

The temporal and spatial aspects of landslides and the elements at risk define how risk is distributed along the railroad. As a consequence understanding the relation between landslide trends in space and time and the site morphology, geology and the triggering mechanisms is essential. This is illustrated with an example where the annual frequency of interaction between slope failure debris and freight trains is estimated, and the associated spatial and temporal variability analysed. 


\section{Study area}

CP's Cascade subdivision is located in southwest British Columbia, along the Fraser River valley, in the Canadian Cordillera. The section between mile 0 (North of Boston Bar) and mile 40 (at Hope, $150 \mathrm{~km}$ East of Vancouver and about $50 \mathrm{~km}$ North of the U.S. Border) of CP's Cascade subdivision was chosen for analysis. This section runs along the west riverbank (Figure 1) and has a history of landslide event records dating back to the 1940s. These records include date, location and volume of the events, as well as the probable source height, weather conditions and any site observations considered relevant by the inspector (Macciotta et al., 2011).

Instabilities documented along this section include rock and soil slides, rockfalls, and snow falls, where rock slope failures account for more than $80 \%$ of the records (Macciotta et al., 2011). Figure 1 (a) shows a typical slope cut along CP's Cascade subdivision. The steepness of the section of the Fraser River canyon between Boston Bar and Yale required steep slope cuts through tectonically altered rock in order to accommodate the track. Figure 1 also shows the scar and deposits of a previous event (a), rock blocks on the track (b) and potential future events (c).

\subsection{Geological and geomorphologic setting}

A proper understanding of the landslide spatial distribution requires understanding the geological and geomorphologic history of the site. From Boston Bar to Hope, the Fraser River lies along the junction between the Coast Mountains and the Cascade Mountains. Several orogenic episodes involved folding and faulting, metamorphism and intrusion (McTaggart and Thompson, 1967). This intense deformation resulted in complexly folded rock masses cut by north-south trending faults, the Hope and Yale Faults in Figure 2 (Monger, 1970). These faults are part of the Fraser River fault zone, and are associated with broad zones of weak materials and differential weathering (Piteau, 1977). A simplified map of the rock units and faults in the area is presented in Figure 2 (Macciotta et al., 2011). Shearing and alteration is common to all rock units, being intensified at contacts between units and near faults.

The study area has been glaciated with the highest peaks staying above the ice. Lower mountains below the Pleistocene ice sheet are rounded (Monger, 1970). The northern 27 miles of the study area, between Boston Bar and Yale, have steeper slopes. Significant lateral erosion by the river is evident in this section. In the southerly 13 miles between Yale and Hope, the valley widens and slopes become less steep. A reason for the valley section change at Yale is the change in the rock mass at this location (Figure 2). Rocks between Yale and Hope (Metamorphic unit 1) would have been more easily scoured and excavated by glacial action than the slope- forming material immediately upstream (Piteau, 1977).

On the west side of the valley between miles 15 and 40, north-trending hills are present with relatively low elevations and gentler topography when compared to the surrounding mountains. These ridges clearly follow the alignments of both the Hope and Yale Faults, and are consequences of their presence. The occurrence of the Hope and Yale faults not only provides sheared and altered rock units, but also influences the geometry of the slopes adjacent to the railroad track (Macciotta et al., 2011). This is illustrated in Figure 3, where typical valley sections between miles 2 to 15 are compared against typical sections between miles 16 to 40 .

\section{$2.2 \quad$ Climate}

The climate through the study area is variable. Moist maritime air movement inland is highly influenced by the north-south trending mountain ranges. As this moist air mass elevates, the west-facing slopes and central peaks are subjected to heavy precipitation. The amount of precipitation then diminishes as the air mass moves towards the interior plateau (Piteau, 1977). Temperature is also expected to be influenced by changes in elevation. Within the study area, there are no significant differences between the average maximum and minimum monthly temperatures. However, daily temperature is highly variable for any given day, typical of microclimates in mountainous areas. Table 1 presents four weather stations located within the study area (locations are shown in Figure 1). Table 1 also presents their location coordinates, elevation 
above sea level, and the available weather data range. These stations are operated by Environment Canada, and their recorded weather data is available to the public.

\section{Legend}

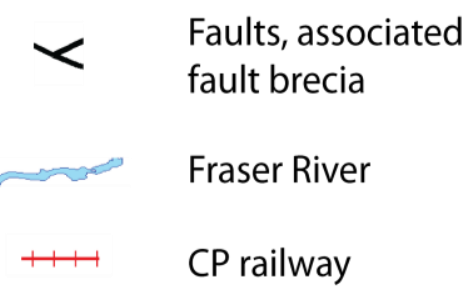

\begin{tabular}{|c|c|c|c|}
\hline & Unit Name & Lithology & Age \\
\hline 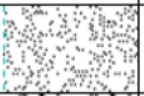 & Sedimentary Unit 2 & $\begin{array}{l}\text { Sandstone, } \\
\text { conglomerate, } \\
\text { argillite }\end{array}$ & Eocene \\
\hline & Intrusive rocks & $\begin{array}{l}\text { Granodiorite, } \\
\text { Quartz diorite, } \\
\text { variably foliated }\end{array}$ & $\begin{array}{c}\text { Mid } \\
\text { Cretaceous } \\
\text { to early } \\
\text { Tertiary }\end{array}$ \\
\hline & Metamorphic Unit 2 & $\begin{array}{l}\text { Pelitic schist, } \\
\text { local } \\
\text { amphibolite, } \\
\text { minor ultramafic } \\
\text { rocks and } \\
\text { siliceous schist }\end{array}$ & $\begin{array}{l}\text { Cretaceous } \\
\text { to Tertiary }\end{array}$ \\
\hline & Metamorphic Unit 1 & $\begin{array}{l}\text { Granite gneiss } \\
\text { with abundant } \\
\text { pegmatite } \\
\text { dikes, pelitic } \\
\text { schist and } \\
\text { amphibolite }\end{array}$ & $\begin{array}{l}\text { Cretaceous } \\
\text { to Tertiary }\end{array}$ \\
\hline 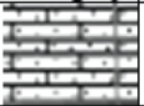 & Sedimentary Unit 1 & $\begin{array}{l}\text { Chert, } \\
\text { limestone, } \\
\text { argillite, slate }\end{array}$ & $\begin{array}{l}\text { Permian to } \\
\text { Jurassic }\end{array}$ \\
\hline
\end{tabular}

$\begin{array}{llllll}0 & 2 & 4 & 6 & 8 & 10\end{array}$ 20 Kilometers

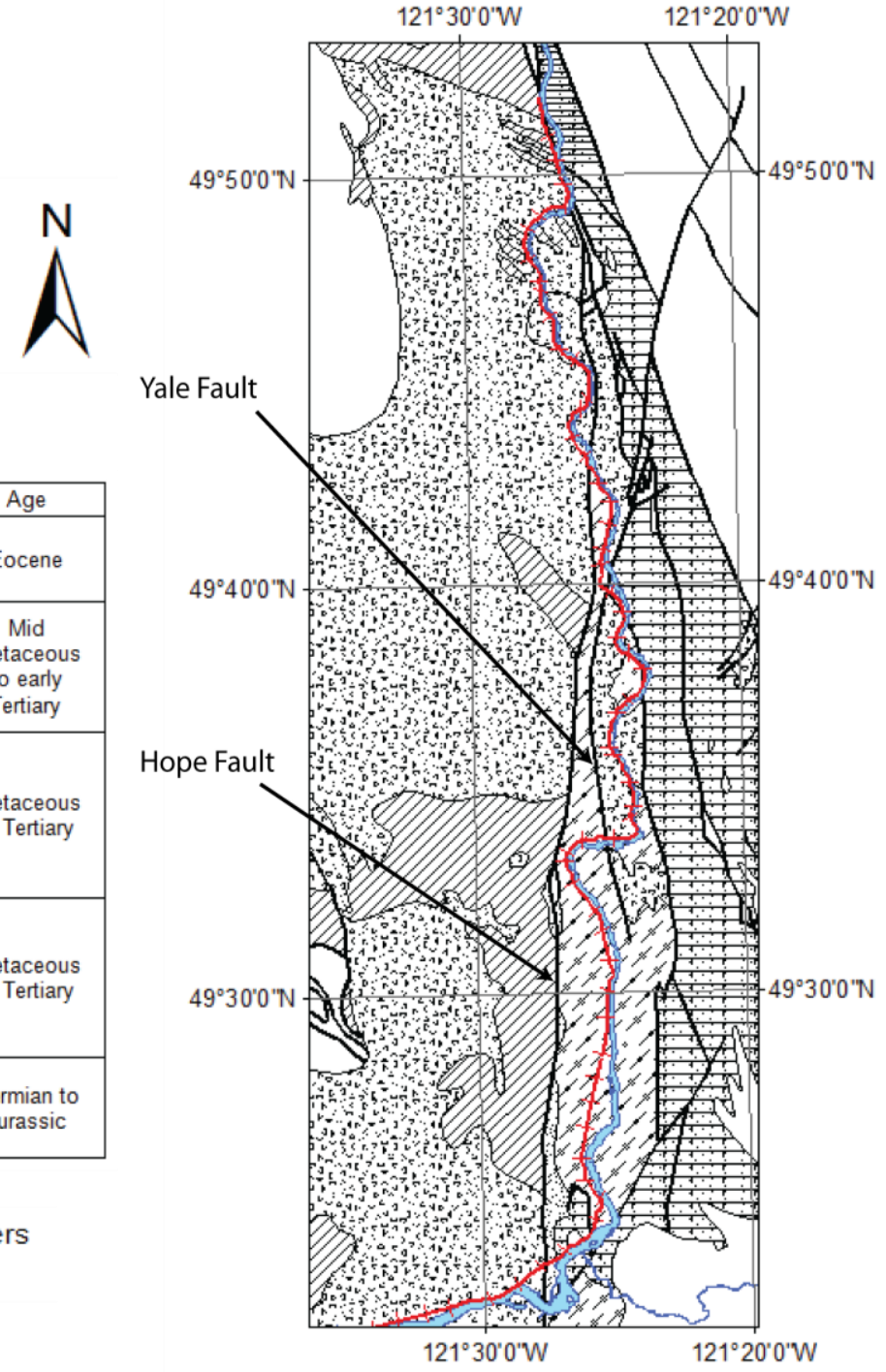

Figure 2 Rock units and faults in the study area (Macciotta et al., 2011)
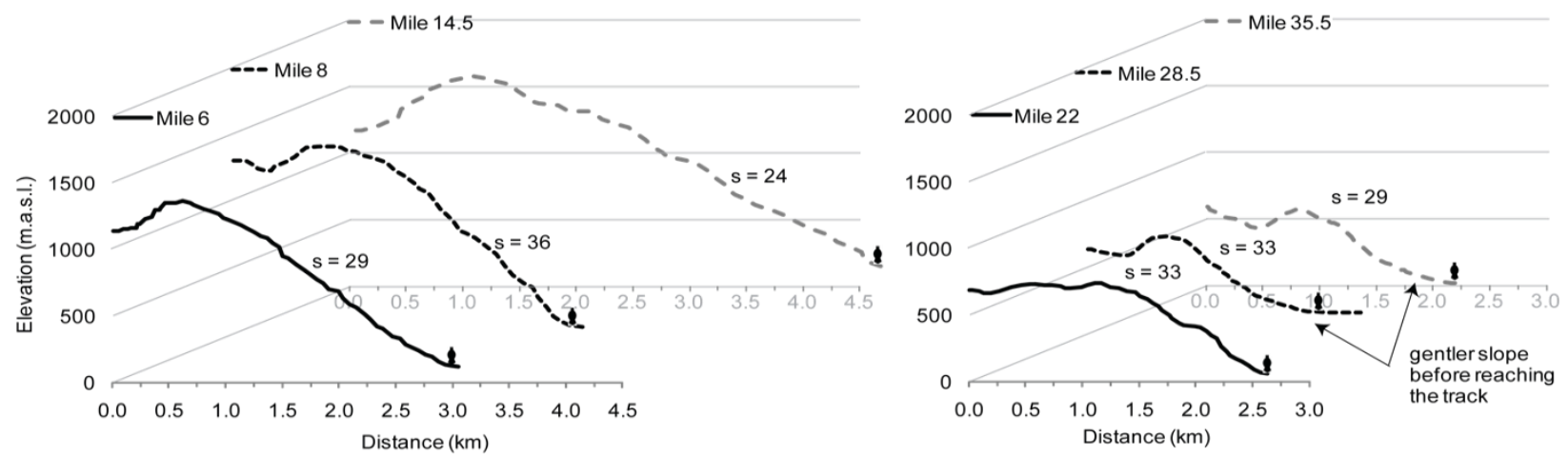

Figure 3 Typical cross sections of the west valley side in the study area for the first 15 miles southwards (left) and for miles 16 through 40 (right) (Macciotta et al., 2011) 
Table 1 Weather stations in the study area, their locations, and the years when the data was acquired at each station

\begin{tabular}{|c|c|c|c|c|}
\hline \multirow{2}{*}{ Station } & \multicolumn{3}{|c|}{ Coordinates and Elevation } & \multirow{2}{*}{$\begin{array}{c}\text { Data Range } \\
\text { (Years) }\end{array}$} \\
\hline & Latitude & Longitude & Elevation (m) & \\
\hline Boston Bar & $49^{\circ} 52^{\prime} \mathrm{N}$ & $121^{\circ} 25^{\prime} \mathrm{W}$ & 200 & $1975-88$ \\
\hline Hell's Gate & $49^{\circ} 46^{\prime} \mathrm{N}$ & $12^{\circ} 27^{\prime} \mathrm{W}$ & 122 & $1951-86$ \\
\hline Yale & $49^{\circ} 34^{\prime} \mathrm{N}$ & $12^{\circ} 25^{\prime} \mathrm{W}$ & 76 & 1985-93 \\
\hline Hope & $49^{\circ} 22^{\prime} \mathrm{N}$ & $121^{\circ} 30^{\prime} \mathrm{W}$ & 39 & 1938-present \\
\hline
\end{tabular}

Figure 4 presents the average maximum and minimum monthly temperatures. This figure also shows the monthly average precipitation and rainfall (Lim, 2007). The weather within the study area can then be summarised as warm, with less precipitation towards the north. Temperature and precipitation vary considerably within the region, and the area appears to be a transition zone between coastal and interior climates (Lim, 2007). In all four station records, precipitation increases in September, peaking in the period between November and January, and decreases in February-March. This trend is highly correlated with monthly temperature changes.
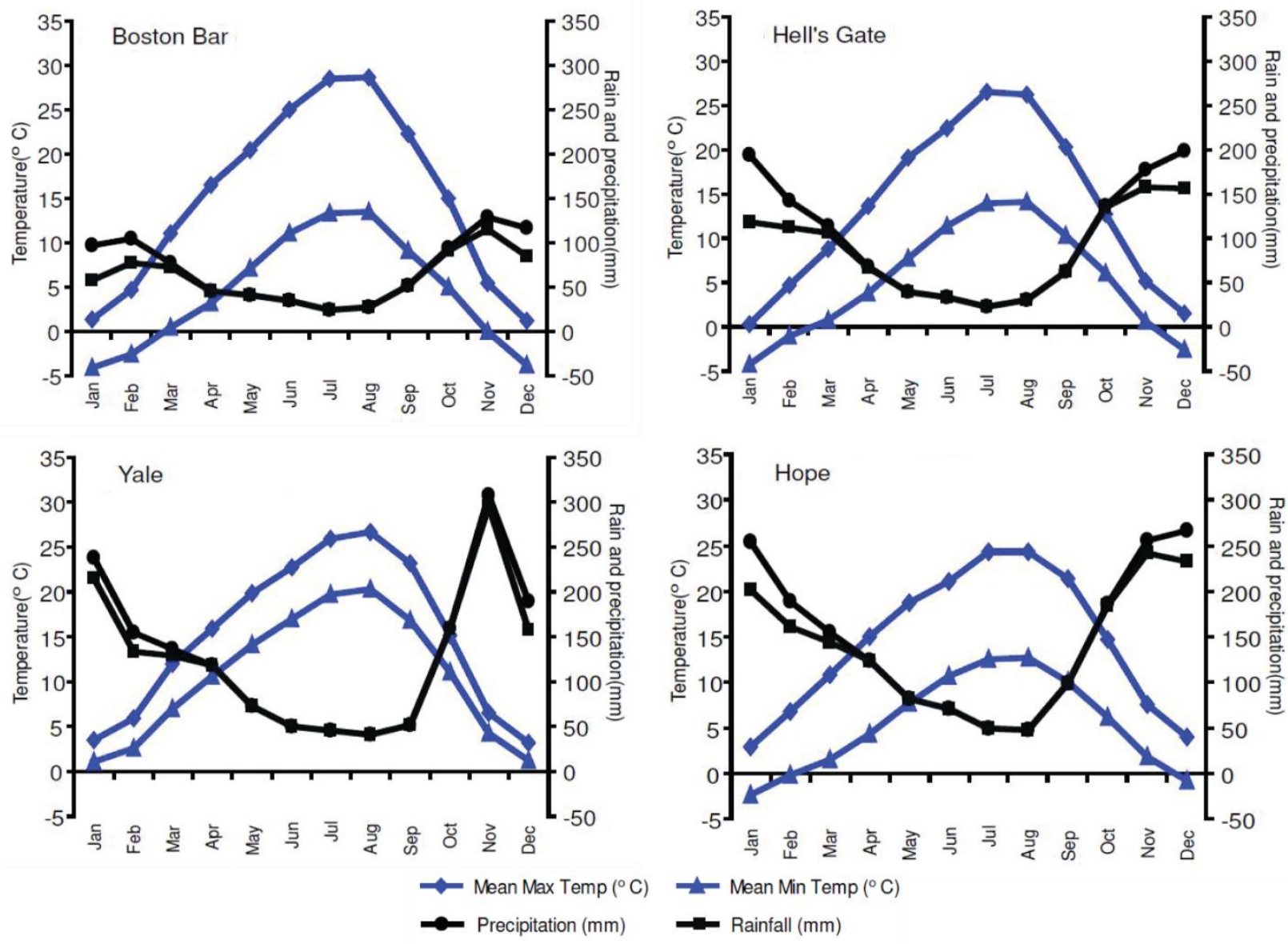

Figure 4 Average monthly precipitation, rainfall, and maximum and minimum temperatures recorded by the weather stations along the study area (Lim, 2007)

\subsection{Landslide frequency}

CP maintains an extensive record of slope instabilities, which dates back to the 1940 s. However, analysis of the relationship between landslide volumes and their frequencies requires the use of a statistically valid 
recording period. Following the recommendations by Hungr et al. (1999), landslide histograms (number of landslides recorded each year) were analysed in order to assess the changes in record keeping standards. A best-fit linear regression for the number of landslides as a function of the year was then calculated. This calculation was done for a fixed end of the recording period (2009) but varying its initial year. A period of consistent landslide record keeping is considered to be represented by the slope of the linear regression approaching zero (horizontal line or a constant average number of landslides per year). Following this approach, the range of data utilised to estimate the annual frequency of landslides corresponds to the years between 1975 through 2009, inclusive.

Landslide volumes in the study area cover several orders of magnitude. The relationship between landslide volume and annual frequency is presented as a volume-cumulative frequency curve (VCF). This plot shows the annual frequency of landslides (vertical axis) of a minimum given volume (horizontal axis). The calculated VCF for the study area is presented in Figure 5. A linear regression with a Log-Log scale was considered appropriate for volumes above $0.6 \mathrm{~m}^{3}$. Extrapolation up to $1,000 \mathrm{~m}^{3}$ seemed reasonable and conservative. For smaller volumes, the cumulative frequency tends to flatten towards the horizontal, most likely due to both underreporting and the physics of the phenomenon.

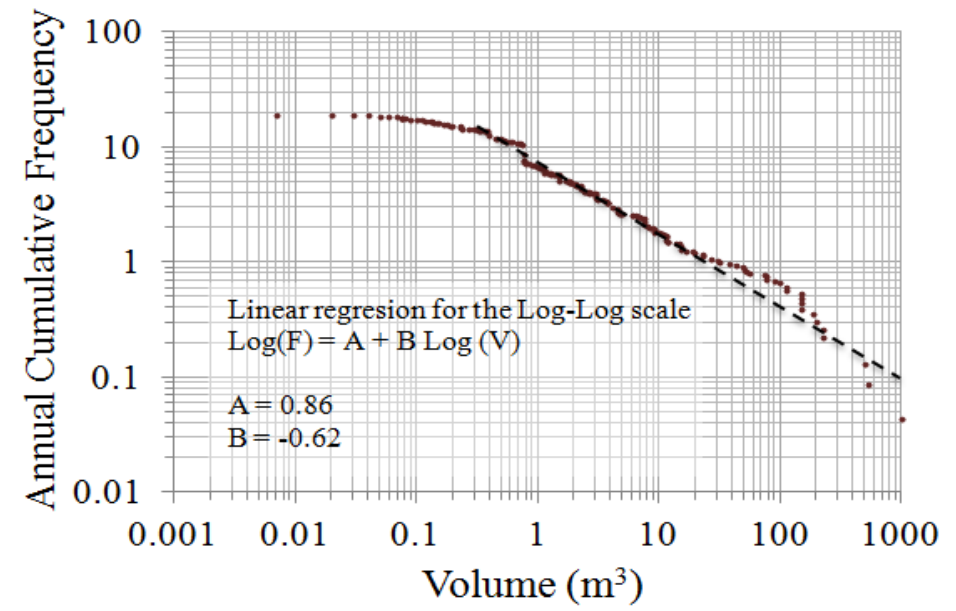

Figure 5 Volume-cumulative frequency curve (VCF) of landslides along the study area

Figure 5 indicates that an average of 20 landslides are recorded each year along the first 40 miles of CP's Cascade subdivision. From these, only seven have volumes over $1 \mathrm{~m}^{3}$, and two have volumes over $10 \mathrm{~m}^{3}$.

\section{$3 \quad$ Spatial and temporal distribution of landslide events}

Understanding the landslides' spatial and temporal distributions and how trends in these are related to morphology, geology and the triggering mechanisms, is important for an efficient slope management program. The extensive record keeping in the study area provides an ideal scenario for this purpose. The knowledge acquired from this particular section can potentially be extrapolated to similar geological and climatic settings when landslide data are scarce or new transportation corridors are being developed.

\subsection{Spatial distribution}

Macciotta el al. (2011) presented an analysis of the geological and morphological setting of this section of CP's Cascade subdivision. They suggested this setting determines the $\mathbf{4 0}$ mile scale distribution of landslide events, while the site specific distribution (peaks and concentration of events) is influenced by local three-dimensional topography immediately up-slope of the railroad. This is illustrated in Figure 6, where the number of landslides is plotted against the railroad mileage. The event distribution correlates with slope angles above a threshold value between 20 and 30 degrees for the initial $50 \mathrm{~m}$ from the track.

In their study, Macciotta et al. (2011) suggested that the presence of hard intrusive rocks between Boston Bar and Yale (miles 2 through 27) led to a steep canyon after glacial scouring. River erosion, mostly 
opposite to valley constrictions caused by alluvial fans, further steepened some of these slopes. The river gradients and typical steep cross sections in this area indicate the slopes are likely to be at an active state of river erosion, thus transitions to flatter slopes before the track alignment are expected to be rare and steep cuts to be necessary to accommodate the railroad alignment. However, the presence of the Hope and Yale faults led to the formation of antiforms about half the height of nearby mountain peaks, where glacial erosion would have reshaped them to rounder hills. This would explain the presence of softer reliefs between miles 15 and 27, limiting the potential source areas when compared to miles 2 through 15 . Between miles 27 and 40, the valley widens when compared to the previous section. This corresponds to a change in lithology to a metamorphosed, sheared unit, where glacial erosion and the presence of the antiforms promoted a softer relief. It is worth noting that between miles 38 to 40 the relief is soft relative to the canyon topography with the exception of a ridge, where the track is located. Here a steep cut was needed to accommodate the railway alignment, being the likely cause for the concentration of events.

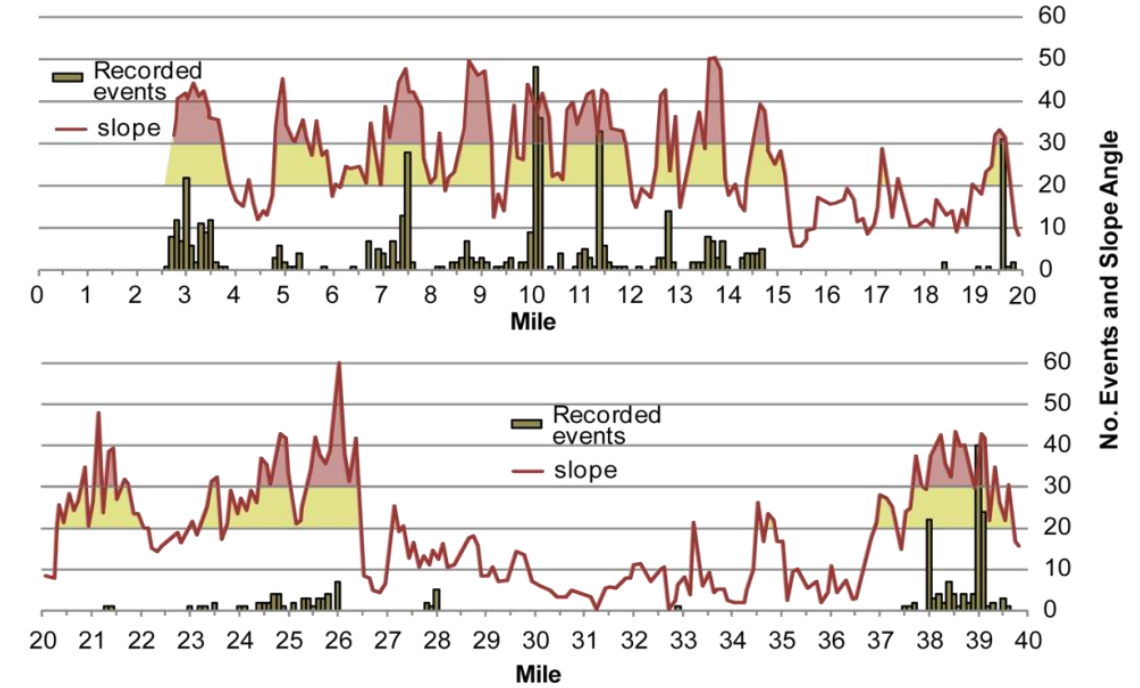

Figure 6 Landslide spatial distribution and average slope angle of the initial $50 \mathrm{~m}$ from the track, west river bank (Macciotta et al., 2011)

CP's records include failures where materials were encountered blocking the tracks and those caught within ditches or behind protective structures. The ratio between records where the material was encountered blocking the tracks to total number of landslides was calculated. This calculation was done for three volume ranges in order to assess any volume dependency. Increasing the number of volume ranges limited the number of records within each range to a level where ratios calculated became unreliable. Table 2 presents the calculated ratios and those adopted for further analysis.

The estimated ratio directly represents the probability a landslide blocked the track, without impacting any train. Any block rolling past the track and into the river is not counted. These ratios were considered approximations of the probability that the displaced material reaches the track or blocks the track.

\subsection{Temporal distribution}

Figure 7 shows the number of landslide events along the study area between 1975 and 2009, inclusive. These were grouped by volume to assess any volume dependent trend. Landslides with volumes up to $10 \mathrm{~m}^{3}$ show great variability in frequency over the recorded period. These failure volumes typically correspond to shallow material detaching from the altered rock faces, and falling onto the railroad track. We expected they would be more susceptible to triggers such as precipitation and freeze-thaw cycles. The intensity and recurrence of these triggers varied over the recording period as did the number of triggered landslides. 
Table 2 Ratio of landslides blocking the railroad track to total landslides. Ratios are presented for all events and for three volume ranges. Ratios used for analysis are also presented

\begin{tabular}{ccccc}
\hline Volume & Total No. Events & $\begin{array}{c}\text { No. Events } \\
\text { Track Blocked }\end{array}$ & $\begin{array}{c}\text { Track Blocked } \\
\text { Ratio }\end{array}$ & Analysis Ratio \\
\hline All events & 535 & 156 & 0.29 & - \\
$0.1-1\left(\mathrm{~m}^{3}\right)$ & 153 & 40 & 0.26 & 0.3 \\
$1-10\left(\mathrm{~m}^{3}\right)$ & 135 & 52 & 0.39 & 0.4 \\
Over $10\left(\mathrm{~m}^{3}\right)$ & 40 & 21 & 0.53 & $* 0.6$ to 1 \\
\hline
\end{tabular}

* 0.6 used for volumes $10-100 \mathrm{~m}^{3}$. A ratio of 1 is used for events over $100 \mathrm{~m}^{3}$.

Larger volume landslides are typically associated with sliding along planar surfaces or wedges. These failures involve deeper rock masses and require through-going shear zones or surfaces to develop. Intense precipitation and freeze-thaw cycles periods would enhance the development of these shears but the trigger, the weather event causing the mass to go from marginal stability to instability, does not necessarily coincide with years of intense weather. This would be reflected in the less variable annual distribution of landslides with volumes over $10 \mathrm{~m}^{3}$ in Figure 7. The weather station at Boston Bar was chosen to evaluate the effect of the annual weather trends in the number of recorded landslides. Figure 8 shows the monthly distribution of precipitation and freeze-thaw cycles recorded by the station. The figure also shows the number of slope failures per month during the recording period. Only those failures between miles 0 through 15 were included (the weather station becomes less representative the farther south the landslide occurs).

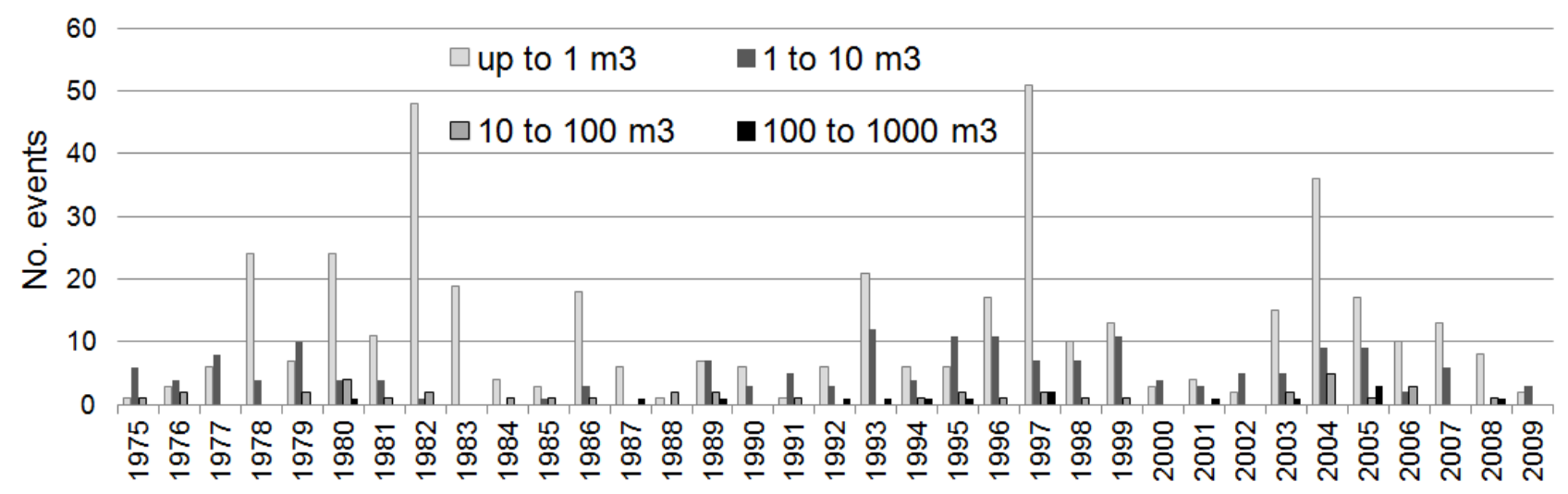

Figure 7 Annual distribution of landslide events for four volume ranges (1975-2009)

Figure 8 suggests there is not a clear correlation between slope failure events and precipitation. However, slope failures seem to occur during periods of freeze-thaw cycles.

The average monthly distribution of landslide events is shown in Figure 9. These were grouped by volume as for the annual distribution in Figure 7. Again, landslide volumes up to $10 \mathrm{~m}^{3}$ show greater variability than the larger volume events. To assess the influence of weather changes throughout the year, the average numbers of landslide events recorded each month were normalised against the average number of events per year and compared against precipitation (Figure 10) and freeze-thaw cycles (Figure 11). 


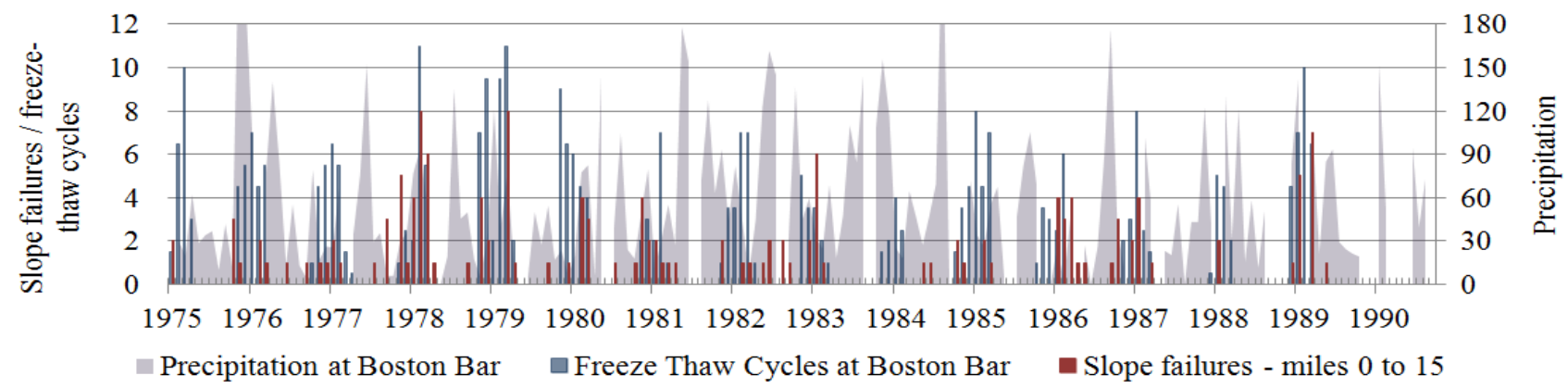

Figure 8 Monthly distribution of landslide events through miles o to 15 and precipitation and freeze-thaw cycles as recorded at Boston Bar-1975 through 1989

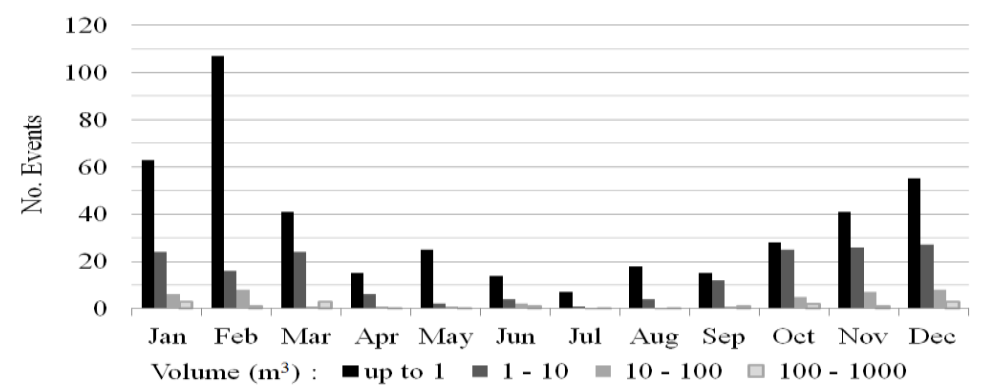

Figure 9 Average monthly distribution of landslides for four failure volume ranges (1975-2009)

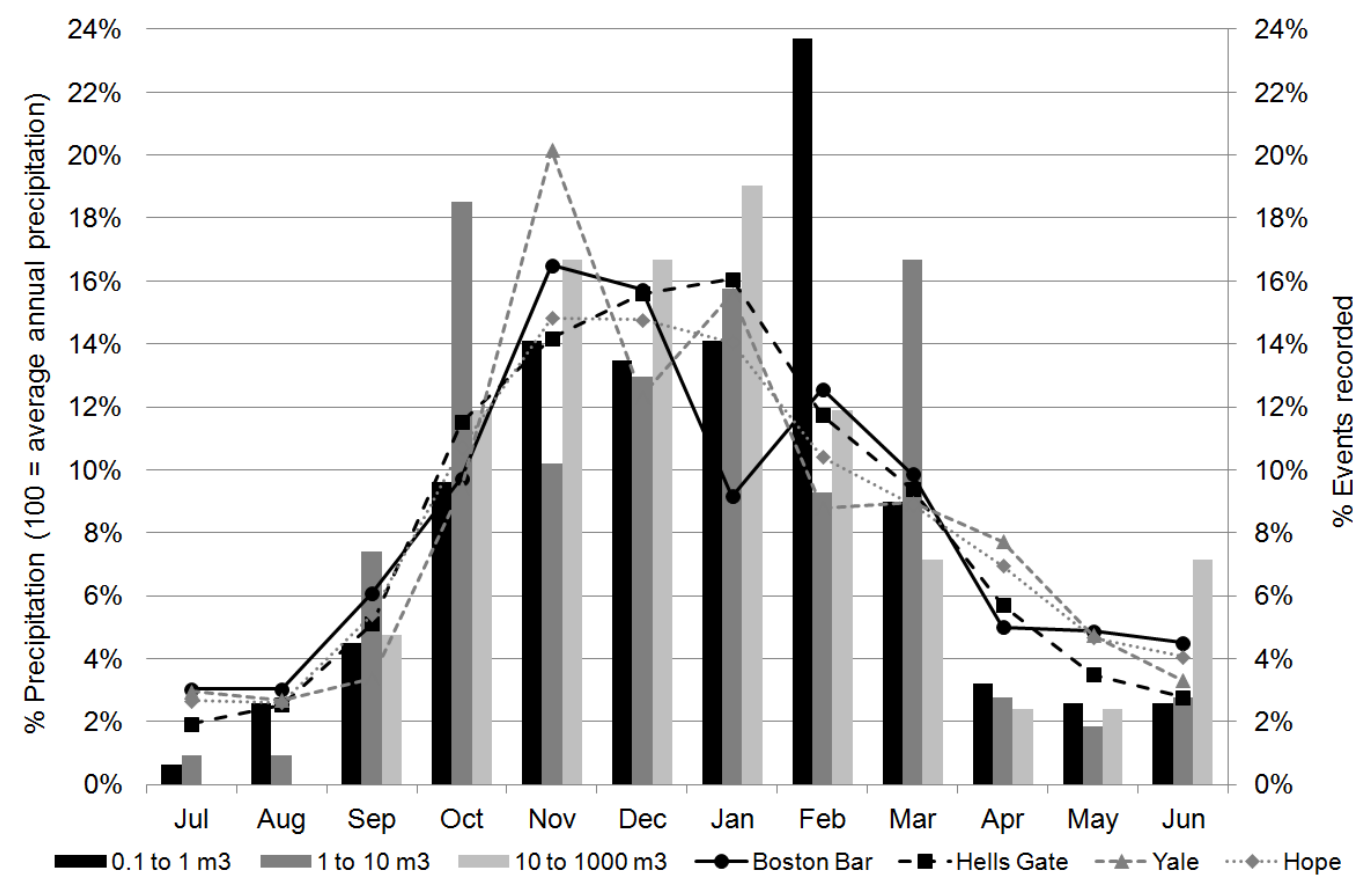

Figure 10 Monthly distribution of slope failure events (normalised to total number of events in each volume range) compared to the monthly precipitation (normalised to total annual precipitation for each station) 


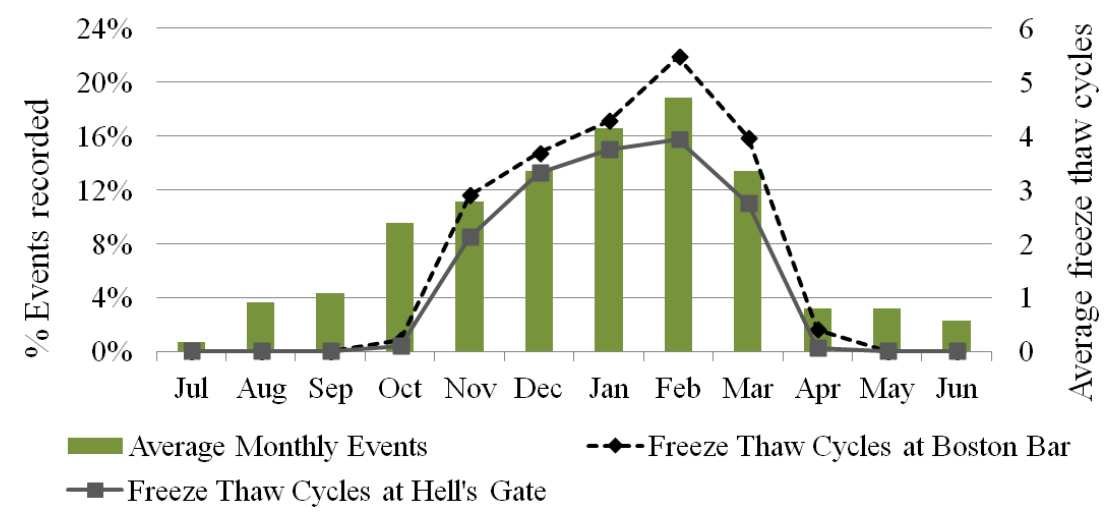

Figure 11 Monthly distribution of landslide events (normalised to total number of events) compared to the average monthly freeze thaw cycles at two weather stations

Figures 10 and 11 suggest good correlations between landslides and both precipitation and freeze-thaw cycles. We believe it is likely that both, together with spring melt of snow cover, act as preparatory factors and triggers for landslides along the study area. However the correlation between landslides and freeze-thaw cycles observed in Figure 8 indicates that these cycles might have, to some extent, a predominant influence on the temporal distribution of landslides. In contrast to the annual distribution shown in Figure 7, the monthly distribution for all landslide volumes follow the same trend, increasing in September-October and decreasing in March. This suggests that landslides with volumes over $10 \mathrm{~m}^{3} \mathrm{might}$ not be correlated to years with precipitation and freeze thaw conditions above average. However the trigger event is more likely to occur during the months of higher precipitation and increased number of freeze-thaw cycles.

\section{$4 \quad$ Temporal-spatial aspects of train operations relative to landslides}

The likelihood that a freight train coincides in space or time with a landslide can be estimated following Bunce et al. (1997) assessing rockfall risks along a highway. Three scenarios are considered representative of railroad operations:

- the displaced material of a landslide impacts a moving train,

- the displaced material of a landslide impacts a stationary train,

- a train encounters a blocked track.

Because each train keeps communication with a central traffic control, the likelihood of other trains being involved in an incident is considered minimal after a first train interacts with a landslide. This section illustrates the methodology to estimate the probability of a train interacting with a landslide for freight train operations considered representative of the study area.

\subsection{Probability that the landslide impacts a moving freight train}

This probability $(\mathrm{P}[\mathrm{S}])$ represents the likelihood that a landslide occurs while a train is moving along the track directly downslope. It can be estimated as:

$$
P[S]=(L \times T) /(V \times 24)
$$

Where:

$\mathrm{L}=$ average train length in $\mathrm{km}$. A length of $2 \mathrm{~km}$ was adopted for analysis.

$\mathrm{T} \quad=$ average number of trains per day. An average of 30 trains was adopted for analysis.

$\mathrm{V}=$ train speed in $\mathrm{km} / \mathrm{h}$. The posted track speed of $40 \mathrm{~km} / \mathrm{h}$ was used in the analysis. 
The adopted values for the parameters in Equation (1) are representative of the study area and render a spatial probability of impact under this scenario $(P[S])$ of 0.063 .

\subsection{Probability that the landslide impacts a stationary freight train}

The probability that a landslide occurs at the time a stationary train occupies the track immediately downslope needs to be assessed considering the railroad infrastructure. The analysis also requires to be disaggregated into site specific analyses or sections of railroad. In locations where sidings exist (adjacent rail track that allows for trains to pass incoming or slower trains), the time a train is stationary can be estimated by considering the number of train passes in that location and the average meet delay. There can be other causes for freights to stop along the track, which are difficult to quantify and foresee. In any case, the probability can be simply approximated as the percentage of time a train is expected to be stationary at the site of analysis. For simplification purposes, this scenario was not considered representative of the study area.

\subsection{Probability that a freight train encounters a blocked track}

The probability of a freight train encountering a blocked track depends on the probability of the failed material reaching and blocking the track and the probability that it does not impact a moving train when falling. This can be estimated as 1-P[S], Equation (1), corresponding to the probability that a landslide occurs when no train is present on the track directly downslope from the failure. For analyses where the probability of a train being stationary along the section is not negligible, $\mathrm{P}[\mathrm{S}]$ should include the intersection probability between the landslide and both cases of a moving and stationary train (see above). The probability that the failed material blocks the track can be estimated through the ratios presented in Table 2.

There is also the possibility that the first vehicle reaching the blocked track is not of the vehicle type in the analysis. It may be a passenger train or maintenance vehicle. The frequency of failed material blocking the track needs to be combined with the probability that the vehicle type is the first to reach the blocked track. A simple ratio of the number of vehicle types in the analysis to the total number of vehicles using the track can be used. This study assumes that a freight train vehicle will be the first to encounter a blocked track. Given that this vehicle type is the most frequent, this assumption was not considered overly conservative.

Because of the history of slope instability along the study section, a Hazard Detection System (HDS) is in place. The HDS consists of a series of wire fences along the section, between the railway track and the cut slope. The spacing between wires is about 25 to $35 \mathrm{~cm}$ and the fence height varies between less than a metre and up to $2 \mathrm{~m}$ in some sections. When a section of track is blocked, it is expected that the material blocking the track would have broken one or more of these wires in its path. This is detected by the system and the nearest track circuit signal shows a track occupation. A slow order for the freight trains is then activated. This implies that the first train to encounter the blocked track will receive warning only if there is a track circuit signal between the activated HDS and the train. The section between track circuit signals is known as the signal block. It is assumed that if the train is outside the signal block where the event occurs, and the HDS is activated, the warning will be effective. The approach adopted for this study assumes the HDS is present along the study area, and constantly operating.

The probability that a warning is not issued can then be assumed to be the probability that the train is inside the signal block when the event occurs:

$$
\mathrm{P}[\text { No warning }]=\mathrm{P}[\text { Inside Signal } \mathrm{Block}]=(\mathrm{B} \times \mathrm{T}) /(\mathrm{V} \times 24)
$$

Where:

$$
\begin{aligned}
& \mathrm{P} \text { [No warning] } \\
& \mathrm{P} \text { [Inside Signal Block] }
\end{aligned}
$$

$=$ probability a warning is not issued given the HDS is activated.

$=$ probability the train is inside the signal block when the event occurs. 
B = distance between the activated HDS and the nearest track-side signal. As this is not known, it can be conservatively estimated as the entire length of the signal block, or as half this length to account for an average distance. A distance of $1 \mathrm{~km}$ was assumed.

$\mathrm{T} \quad=$ number of trains per day. 30 trains were used for analysis.

$\mathrm{V}=$ train speed in $\mathrm{km} / \mathrm{h} .40 \mathrm{~km} / \mathrm{h}$ was used for analysis.

The values adopted are representative of the study area and render a probability that a freight train does not receive a warning given the track is blocked (P[No warning]) of 0.031 .

The analysis also assumes that if warned, the train will be travelling at restricted speed. This restricted speed (slow order) is variable and is taken, as a maximum, half the track speed. Records show that most slow orders in this section are to keep speeds of about $16 \mathrm{~km} / \mathrm{h}$, which allows for the train to come to a stop given a blocked track is observed.

\section{$5 \quad$ Annual frequency of interaction between freight trains and landslide, and its spatial and temporal distribution}

The annual frequency of interaction between freight trains and landslide events along the study area can be estimated by combining the landslide frequency, the likelihood that material reaches and blocks the track, and the temporal-spatial probability that the freight train coincides with the failure event. Table 3 presents the calculations followed to estimate this frequency. The consequences of a train - landslide interaction is highly dependent on the volume of material moved. So the frequency of interaction was estimated for four ranges of slope failure volumes. The frequency for all landslide volumes is also shown.

The annual landslide frequency for each volume range is directly extracted from the VCF curve in Figure 5. In a similar way, the ratio of events reaching (or blocking) the track is extracted from Table 2. These two combined by simple multiplication provide an estimation of the annual frequency of landslides reaching (or blocking) the track. The next step is to combine this frequency with the temporal-spatial probability that the train coincides with the failure event for the two scenarios considered (debris impacting a moving train and train encounters a blocked track). Then, by addition of these two, the annual frequency of train-landslide interaction is estimated.

\section{Table 3 Frequency of interaction between freight trains and landslides}

\begin{tabular}{cccccc}
\hline & \multicolumn{5}{c}{ Volume $\left(\mathbf{m}^{\mathbf{3}}\right)$} \\
& $\mathbf{0 . 1 - 1}$ & $\mathbf{1 - 1 0}$ & $\mathbf{1 0 - 1 0 0}$ & Over 100 & All \\
\hline Annual slope failure frequency & 11.76 & 5.50 & 1.32 & 0.42 & 19.00 \\
Ratio of events blocking / reaching the track & 0.30 & 0.40 & 0.60 & 1.00 & 0.37 \\
Annual frequency of events blocking / reaching & 3.53 & 2.20 & 0.79 & 0.42 & 6.94 \\
$\quad$ the track & & & & & \\
Annual frequency for scenario 1 & 0.22 & 0.14 & 0.05 & 0.03 & 0.43 \\
Annual frequency for scenario 2 & 0.09 & 0.06 & 0.02 & 0.01 & 0.12 \\
Annual frequency of train-slope failure interaction & 0.31 & 0.20 & 0.07 & 0.04 & 0.56 \\
\hline
\end{tabular}

It is believed that for a given landslide volume, the consequences of a train impacting a blocked track is different from the consequences of debris impacting a moving train. For that reason, the annual frequency of train - landslide interaction under each scenario is also presented in Table 3. It can be observed that the frequency of interaction along the study area is dominated by the scenario where the landslide debris impacts a moving train. This corresponds to a high density of the HDS and track circuit signals in the area. 
When a section of track is blocked, it becomes unlikely that a train is inside the signal block and receives no warning.

Figure 12 presents the annual frequency of train-landslide interaction distributed along the study area. This figure highlights the miles where the interaction is most likely. The advantage of this approach when compared to analysing just the spatial distribution of landslide events is that an absolute value for the frequency of interaction is obtained. Also, this approach accounts for the different ratios of debris reaching the track for the different slope failure volumes. It can be observed that the hazardous miles ( 3 to 15,20 , 24 to 26,28 and 28 to 40 ) all pose a similar order of magnitude for the frequency of train-landslide interaction.

Figure 13 shows the annual frequency of train-landslide interaction distributed for each month of the year and for different landslide volumes. It can be observed that the frequency of trains interacting with landslide debris volumes over $100 \mathrm{~m}^{3}$ is low (once every 25 years) and doesn't show considerable variation throughout the year when compared to failures of less volume. It is expected the consequences of train-landslide interactions are highly volume-dependent. As such, the distribution shown in Figure 13 is expected to have a significant impact on the distribution of risk throughout the year.
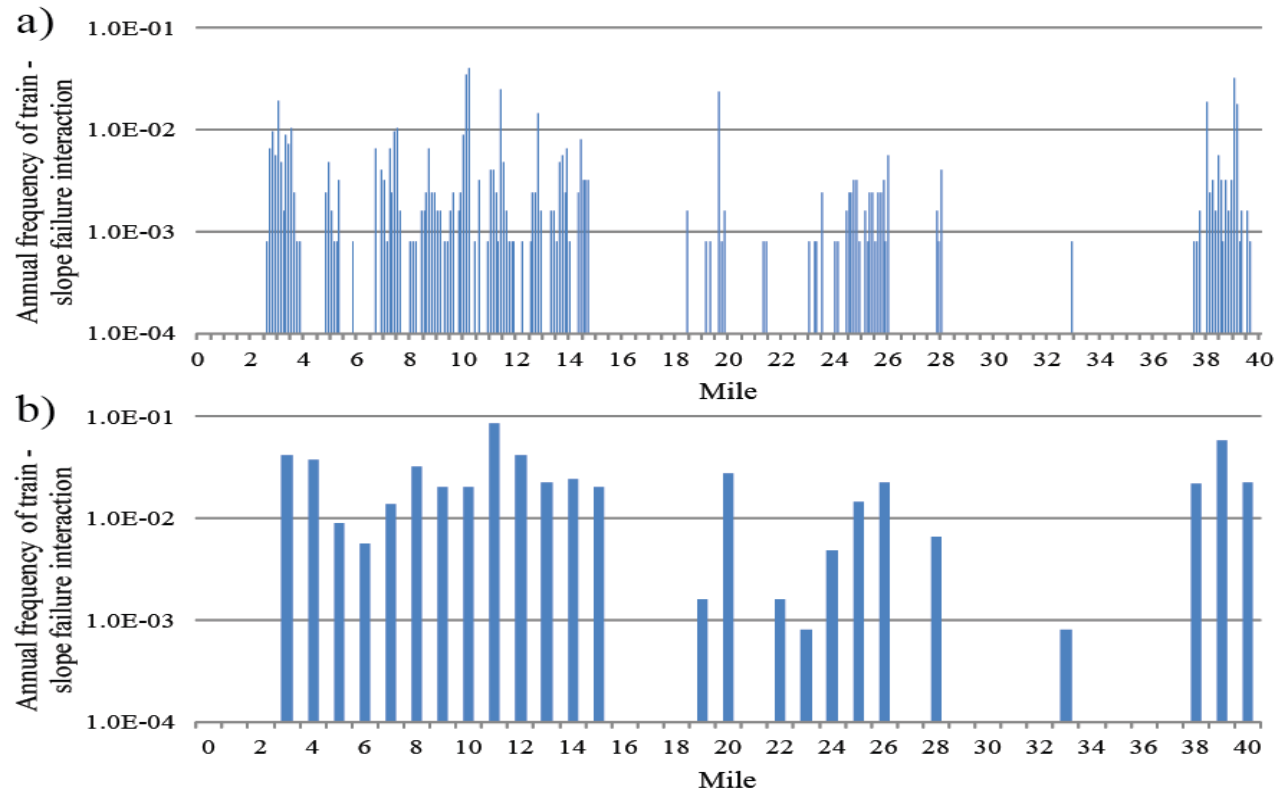

Figure 12 Annual frequency of interaction between freight trains and landslides distributed along the study area;

(a) per 1oth of a mile; (b) per mile

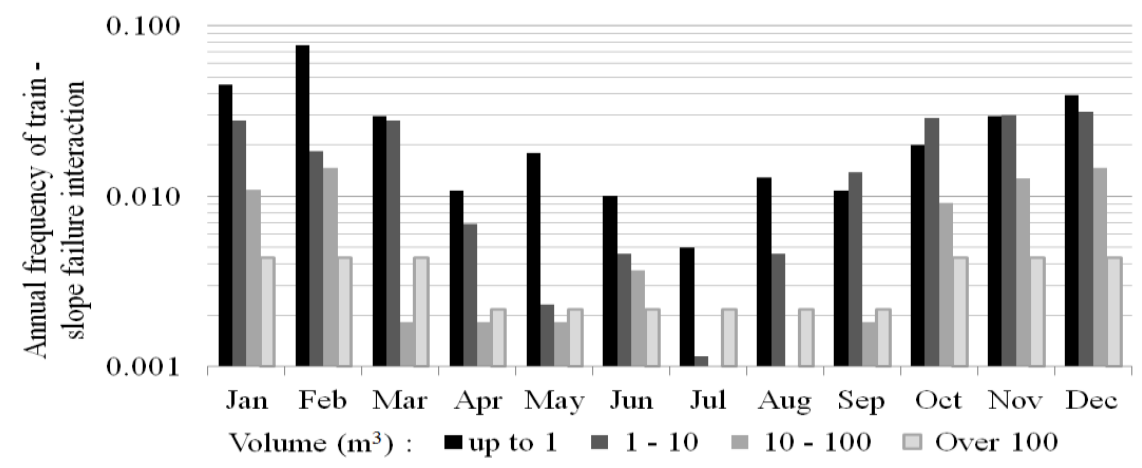

Figure 13 Monthly frequency of interaction between freight trains and landslides for four volume ranges 


\section{Conclusions}

The spatial and temporal aspects of landslide events along a section of the Canadian Pacific Railway Cascade subdivision were analysed. Not surprisingly, the spatial distribution was found to correlate to the different lithologic units in the area as well as the presence of a major fault system and the history of glaciations. At a smaller scale, the events seem to be concentrated at locations where the slope immediately next to the railroad alignment exceeds a threshold value between 20 and 30 degrees.

Temporally, the events are concentrated through the months of greater precipitation and freeze-thaw cycles. The temporal distribution of landslides up to $10 \mathrm{~m}^{3}$ seem to be more influenced by weather events acting as triggers, which is consistent with previous studies in similar contexts. For landslides of larger volumes, weather events appear to enhance the progressive reduction of the cut-slope stability. The trigger event causing the slope to change from a state of marginal stability to instability will likely occur during the annual wet season (or more freeze-thaw cycles) however does not necessarily coincide with years of precipitation or freeze-thaw cycles above average. This was suggested by a more uniform distribution of the larger events when plotted against the year of occurrence. This annual relationship between landslide occurrence and weather is not fully resolved and the wide year-to-year range in landslide activity remains a matter for further research. In any case, and as expected, weather and the geological/morphologic context of the area seem to be the driving factors for slope instabilities in the area. The improved knowledge acquired, however, allows the assessment of the most hazardous locations and periods in a quantitative manner.

A simplified method for estimating the annual frequency of interaction between freight trains and landslides was presented and applied in the study area. Simplified assumptions were made such as neglecting other vehicle types, assuming the HDS is working $100 \%$ of the time, considering appropriate reaction of the train crew when receiving a warning and spotting a blocked track, among others. The method, however, provides a practical means of quantifying the frequency of freight trains interacting with landslides. If required, the simplifications and assumptions made in this study could be overcome by building a more comprehensive, but complex model. The method also allows for the spatial and temporal distribution of train-landslide interaction frequency to be analysed in absolute terms. It is expected the analysis will become the basis of a robust tool that will aid in the decision making regarding the allocation of resources for risk mitigation purposes along transportation corridors.

This paper presented, in a simplified manner, how to integrate gained understanding of slope failures spatial and temporal trends with the exposure of the elements at risk. This allows better understanding the risks associated with the slopes analysed and their variability in space and time, in a quantitative manner.

\section{Acknowledgement}

This work was supported by the Canadian Rail Research Laboratory, Canadian Railway Ground Hazard Research Program, and the Natural Sciences and Engineering Research Council of Canada.

\section{References}

Bunce, C.M., Cruden, D.M. and Morgenstern, N.R. (1997) Assessment of the hazard from rock fall on a highway, Canadian Geotechnical Journal, Vol. 34, pp. 344-356.

Dorren, L.K.A. (2003) A review of rock fall mechanics and modeling approaches, Progress in Physical Geography, Vol. 27(1), pp. 69-87.

Evans, S.G. and Hungr, O. (1993) The assessment of rock fall hazard at the base of talus slopes, Canadian Geotechnical Journal, Vol. 30, pp. 620-636.

Guzzetti, F., Reichenbach, P. and Ghigi, S. (2004) Rockfall hazard and risk assessment along a transportation corridor in the Nera Valley, Central Italy, Environmental Management, Vol. 34(2), pp. 191-208.

Hoek, E. (2007) Practical rock engineering, 2007 electronic edition, RocScience, viewed June 2013, http://www.rocscience.com/ education/hoeks_corner.

Hungr, O., Evans, S.G. and Hazzard, J. (1999) Magnitude and frequency of rock falls and rock slides along the main transportation corridors of southwestern British Columbia, Canadian Geotechnical Journal, Vol. 36, pp. 224-238. 
Hunt, R.E. (1992) Slope failure risk mapping for highways: methodology and case history, Transportation Research Record 1343 , pp. 42-51.

Lan, H., Martin, C.D. and Lim, C.H. (2007) Rock fall analyst: A GIS extension for three-dimensional and spatially distributed rock fall hazard modeling, Computers and Geosciences, Vol. 33, pp. 262-279.

Lan, H., Martin, C.D., Zhou, C. and Lim, C.H. (2010) Rock fall hazard analysis using LiDAR and spatial modeling, Geomorphology, Vol. 118, pp. 213-223.

Lim, C.H. (2007) A process model for rock fall hazard assessment - Draft, Ph.D. thesis, University of Alberta, Edmonton, Canada.

Macciotta, R., Cruden, D.M., Martin, C.D. and Morgenstern, N.R. (2011) Combining geology, morphology and 3D modelling to understand the rock fall distribution along the railways in the Fraser River Valley, between Hope and Boston Bar, B.C, in Proceedings International Symposium on Rock Slope Stability in Open Pit Mining and Civil Engineering, Slope Stability 2011, E. Eberhardt and D. Stead (eds), 18-21 September 2011, Vancouver, Canada, Canadian Rock Mechanics Association.

McTaggart, K.C. and Thompson, R.M. (1967) Geology of part of the Northern Cascades in Southern British Columbia, Canadian Journal of Earth Sciences, Vol. 4, pp. 1199-1228.

Monger, J.W.H. (1970) Hope map-area, west half - British Columbia, Paper 69-47, Geological Survey of Canada, Department of Energy, Mines and Resources.

Piteau, D.R. (1977) Regional slope stability controls and related engineering geology of the Fraser Canyon, British Columbia, Landslides - Reviews in Engineering Geology, GSA, Vol. 3, pp. 85-111.

Roberds, W. (2005) Estimating temporal and spatial variability and vulnerability, Landslide risk management, in Proceedings International Conference on Landslide Risk Management, O. Hungr, R. Fell, R. Couture and E. Eberhardt (eds), 31 May-3 June 2005, Vancouver, Canada, A.A. Balkema, pp. 129-157. 
